\title{
The effects of correlated colour temperature on wayfinding: A study in a virtual airport environment ${ }^{\text {th }}$
}

\author{
Ozge Kumoglu Suzer ${ }^{\mathrm{a}, *}$, Nilgun Olgunturk ${ }^{\mathrm{a}, *}$, Dilek Guvenc ${ }^{\mathrm{b}}$ \\ a Department of Interior Architecture and Environmental Design, Faculty of Art, Design and Architecture, Bilkent University, 06800 Bilkent, Ankara, Turkey \\ ${ }^{\mathrm{b}}$ Department of Mathematics, Faculty of Science, Bilkent University, 06800 Bilkent, Ankara, Turkey
}

\section{A R T I C L E I N F O}

\section{Keywords:}

Wayfinding

Colour temperature

Lighting

Virtual environment

Airport

\begin{abstract}
A B S T R A C T
This study was designed to explore the effects of lighting's correlated colour temperature (CCT) on wayfinding performance in airports and to compare different CCTs to understand their effects on wayfinding performance. The experiment was conducted in a single phase with the participation of three different groups of university students who experienced the virtual airport environment in three different lighting settings: $3000 \mathrm{~K}, 6500 \mathrm{~K}$ and $12,000 \mathrm{~K}$.

The participants were asked to direct the researcher from the starting point to the final destination. It was found that CCT has no significant effect on wayfinding performance in terms of time spent, total number of errors, total number of decision points or route choice. However, CCT does have a significant effect on hesitation; the number of hesitations decreased when CCT increased from $3000 \mathrm{~K}$ to $12,000 \mathrm{~K}$. Gender difference was also explored regarding hesitations in this study.
\end{abstract}

\section{Introduction}

Wayfinding is the ability to reach a destination in a short time without experiencing fear or stress [66]. The travelling condition is one of the most stressful wayfinding processes because time is a crucial issue. Airports are labyrinth-like structures in which people are likely to lose themselves or at least get confused to slow down their flow. Design may help in wayfinding by enabling faster route following and easing stress and annoyance in the process. The act of wayfinding can be viewed as a continuous sequence of problem-solving tasks requiring information about the environment [64].

Arthur and Passini (1992: 25) explained wayfinding as a spatial problem-solving activity comprising the three specific but interrelated processes of "decision making and the development of a plan of action; decision executing, which transforms the plan into appropriate behaviour at the right place in space; [and] information processing, understood in its generic sense as comprising environmental perception and cognition, which, in turn, are responsible for the information basis of the two decision-related processes." The authors also defined cognitive mapping as part of environmental perception, where cognition is basically a source of information for making and executing a decision. At this point, understanding the difference between perception and cognition is important. Perception is defined as the process of obtaining information through the senses; cognition is defined as understanding and being able to manipulate information [4]. Obtaining information is not enough to be able to find one's way; understanding and manipulating the information is also an essential part of the wayfinding process.

Light is one of the most important physical factors influencing the perception of a space, and it may also affect wayfinding performance. Light is an energy that allows people to experience the visual world, thus it affects visual performance. Moreover, light has a considerable effect on how people perceive the physical qualities of a space; it also gives meaning and emotion to that space [40]. Lighting, as a controlled application of light, can change the human perception in different ways. Egan and Olgyay explained (2002) the visual experience as a combination of seeing and interpreting the environment with many different cues. Previous research in the literature reported that lighting has a significant effect on perception of a space, space evaluation, emotional responses and preferences, physiological and psychological comfort [1,6-8,19,23,25,38,39,50-52,59,80,81]. Therefore, lighting should be considered an essential design element, along with form, colour and texture, and like those elements, as a significant contributor to spatial compositions.

Colour temperature is an aspect of lighting, and concerns the appearance of light. It is the "colour" of especially white light, we consider

\footnotetext{
This paper was recommended for publication by Richard H.Y. So.

* Corresponding authors.

E-mail address: ozge.kumoglu@bilkent.edu.tr (O.K. Suzer).
} 
here, which when energized, ranges from a very cool white to a very warm white [24]. The sensation of colour is explained via three distinct qualities: of hue, value (lightness) and chroma (saturation, purity). Hue is the name of a colour, such as red, orange, and yellow. It allows us to differentiate one colour from another [22]. White, gray and black are achromatic colours, thus considered to be colours without hue [68]. Value, also known as lightness, represents the lightness or darkness of a colour [34], and allows us to distinguish a light colour from a dark one [57]. Value becomes an important aspect for making contrast more effective. Chroma, also known as saturation or colourimetric purity, is the strength and vividness of a colour. It represents the amount of pigment in a colour [22] and is related to intensity. Colour temperature in degrees Kelvin (K) from an electric light source expresses warmth or coolness (e.g., yellowish-white, bluish-white or neutral), not a spectral energy distribution or a physical temperature.

There is much research on the effects of CCT on performance $[32,33,39,41,51]$, reporting a significant effect from a light's CCT on performance in long-term recall, recognition tasks, problem-solving tasks, free recall tasks, performance appraisal tasks, mood, spatial perception and memory. To the authors' knowledge there is no research in literature exploring the relationship between CCT and wayfinding performance. Wayfinding is a three-dimensional performance task differing from well-studied two-dimensional paper-based tasks. Exploring the effect of CCT on wayfinding performance is important because any significant effect would benefit users' performance in high-density, stressful environments where white artificial lighting is extensively used, such as airports. This study purports to fill in the gap in wayfinding and lighting research, exploring the effect of CCT in wayfinding.

\subsection{Wayfinding performance criteria}

Wayfinding performance has been measured by various tasks in previous studies. Ruddle and Lessels [71] proposed three levels of a virtual environment (VE) metric based on: "(1) users' task performance (time taken, distance travelled, and number of errors made), (2) physical behaviour (locomotion, looking around, and time and error classification, (3) decision making (i.e. cognitive) rationale (think aloud, interview, and questionnaire)". The authors explained Level 1 (users' task performance metrics) as metrics that measure how well a user performs a task, which for wayfinding involves a user finding a particular place; Level 2 (physical behaviour metrics) as metrics that provide information about what a user is doing during a given task, not just how long he or she takes or how accurately he or she performs and Level 3 (rationale metrics) as metrics that can provide an explanation for why users exhibit given behaviours. This study focuses on the effect of CCT on travellers' wayfinding performance. Ruddle and Lessels [71] Level 1 metrics are included as wayfinding performance criteria for this study. The explanations of measurements and of previous studies in which these measurements are used are given below.

Time Spent: According to the definition of Peponis et al. [66], wayfinding is the ability to reach a destination in a short time without experiencing fear or stress. The time spent during the wayfinding task is an important criterion by which to measure wayfinding performance. The criterion classifies performance in terms of the amount or proportion of time users spend while performing the task. Previous studies $[15,20,45,56,76,77]$ found that wayfinding time is significantly correlated with errors (wrong turns) and hesitation frequency. Travellers who experienced more errors and hesitations spent more time searching for the destination.

Error: The number of errors that users make during wayfinding is frequently used as a measure of performance. The type of error that is most commonly identified in wayfinding is a miss, which occurs when a user travels within sight of a given location without turning to look at it or takes a wrong turn [73,74].

Decision Points and Route Choice: Golledge [29] defined wayfinding as the process of making decisions and following a path or route between an origin and a desired destination. Decision points are closely related to route choice in wayfinding. As Raubal and Egenhofer [69] explained, decision points are most apparent whenever a person has the opportunity to select among different paths. In other words, if a traveller chooses a long route, the number of decision points increase, which influences the difficulty of the wayfinding task. Arthur and Passini [4] and Best [5] stated that the number of decision points directly influence the difficulty of performing a wayfinding task, and they found a correlation: the more choice points, the more likely the respondent was to report becoming lost. Because of this reason, Raubal and Egenhofer [69] distinguished between points where subjects have one obvious choice to continue the wayfinding task and points where subjects have more than one choice to continue the wayfinding task. They called points with "choice $=1$ " enforced decision points, and points with "choices $>1$ " decision points.

Hesitation: Hesitations that users experience during a wayfinding task are frequently used as a measure of performance. A hesitation is generally defined as a full stop made by the participant $[12,20,31,45$, $56,69,76,77,84]$.

\subsection{Wayfinding research in virtual environments}

Wayfinding research can be investigated either in real-life settings or through laboratory experiments. Nowadays, VEs, which allow the simulation of three-dimensional environments on a computer, are increasingly used. In the real world, it is hard to control all the variables, and in some cases it is almost impossible. To examine the effect of a specific condition, one needs to control all the variables in the physical setting, and this is more possible in simulated settings.

Previous findings showed that using VEs in spatial cognition research is more advantageous than using real environments because the VE environment is more controllable, it can be changed quickly and easily participants are able to operate in a self-determined way, nearly all kinds of environments can be simulated and navigation can be measured online [62]. Furthermore, participants can acquire knowledge about directions and distances $[2,88]$, develop route and survey knowledge $[28,61]$ and navigate effectively in a VE $[18,75]$. Aside from the positive aspects, VEs also have some limitations, especially desktop VEs, for example, a lack of proprioceptive sensory information [89]. Proprioception is locating oneself in an environment and proprioceptive sensory information is about understanding distance accurately. Previous research has agreed that acquiring distance knowledge is different in VEs than in real environments $[28,30,72,82,89]$; in the former, although users cannot acquire accurate distance knowledge, evidence indicates that proprioceptive feedback might not be crucial for spatial learning. Waller et al. [85] showed that there was no difference between learning the spatial representation of mazes in wire-frame virtual and real-world conditions. Furthermore, Westerman et al. [87] showed that navigation efficiency was poorer in an immersive VE than in a desktop VE. A desktop VE, which is widely used and appreciated for how it allows investigation of the cognitive processes of spatial cognition $[28,62,72,75]$, was preferred for the current study. However, desktop virtual systems do not allow for integrating self-motion as a real-world environment would [89]. Unlike proprioceptive feedback, self-motion might be more critical for tasks that are more perception based, such as path integration, than for tasks that more cognitively based [37]. Richardson et al. [70] suggested that similar cognitive mechanisms are involved in desktop virtual and real learning conditions, but that participants are susceptible to disorientation after rotation. The use of an immersive virtual system, in which updating at least the head position would be possible, could ameliorate spatial learning, but this is also discussed critically [87]. In spite of the advantage of being completely immersed in the virtual world, participants in immersive systems commonly experience after effects, such as symptoms of motion sickness, balance disturbance, and drowsiness [78].

In this study, conducting an experiment on a desktop VE had the 
advantage of being able to easily change the colour temperature of lighting elements in a large-scale environment, namely an airport. Within the scope of this study, the wayfinding performance criteria were prepared considering the limitations of the desktop VE. For instance, estimating distance was not a criterion for this study.

\subsection{Gender difference and wayfinding performance}

In 1995, Voyer et al., stated that gender difference is a controversial issue in the literature, not only in wayfinding but also in spatial ability in general. Although gender differences are not uniformly found, when they are found they often favour males $[3,49,53]$. However, gender difference is still preserves its' uncertainty to this day because there are many individual differences and other factors that may have effect on wayfinding and spatial navigation $[10,13-17,35,48,58,62,63,67$, 79,82].

Lawton [44] reported that gender differences exist due to different strategies used to solve orientation problems, and explained that males use an orientation strategy while females use a route strategy. That is, females are more likely than males to report that they rely on landmarkbased route information, whereas males are more likely to report that they orient to global reference points (the cardinal directions of north, west, south or east, or the position of the sun) $[43,44]$. In other words, males tend to situate themselves in an environment by the aid of global reference points, which is basically an orientation strategy, whereas females tend to use a route strategy, where they search for environmental cues such as landmarks, architectural differentiations and distinctions.

Environmental cues are factors that increase awareness about the environment and facilitate a wayfinding task. Osmann and Wiedenbauer (2004) explored the role of landmarks on wayfinding. The participants learned a route with a slide presentation, and then had to recall the inherent landmarks to find their way in a virtual environment. The results showed that females relied more on landmarks than males did. Sandstrom et al. [76] investigated the use of different distal cues comparing males and females in a VE Morris Water Maze task. It is found that that females rely predominantly on landmark information, while males more readily use both landmark and geometric information. In other words, it is reported that males and females employ different types of strategies and focus on different properties of the environment. Additionally, it is also reported that when landmark and geometric information were available, males were faster than females at reaching a hidden target.

Gender differences also have been found in measures such as pointing accuracy and number of errors in navigation, favouring males $[9,20,45]$. A pointing task measures the amount of control over information that is needed to navigate successfully in an environment. Lawton [43] also found that females make more errors in pointing tasks and are less confident than males. Conflicting results have been found for gender differences and sense of direction. Bryant [9] found that males rated their sense of direction higher than females rated their own sense of direction. However, both Kozlowski and Bryant [42,83] found no gender differences in sense of direction. Tlauka et al. [82] explored the spatial knowledge acquisition in a virtual shopping centre comparing males and females. Spatial knowledge acquisition of participants' was then tested in a battery of tasks including wayfinding, directional and distance estimates, and a map placement task. In the majority of comparisons made, there were significant differences favouring males.

Gender differences also have been found in measures such as pointing accuracy and number of errors in navigation, favouring males $[9,20,45]$. Devlin and Bernstein [20] found that males made significantly fewer errors compared to females when doing computer simulated wayfinding. Galea and Kimura [26] and Devlin and Bernstein [20] found consistent results on gender differences. Females were found to be taking longer to complete wayfinding tasks and were less accurate in terms of wayfinding performance compared to males. A pointing task measures the amount of control over information that is needed to navigate successfully in an environment. Lawton [43] also found that females make more errors in pointing tasks and are less confident than males. There has been a significant advantage of males for spatial route learning through an unfamiliar environment and on tasks requiring survey knowledge, such as; pointing directions, drawing a sketch map and estimating travel distances $[10,14,16,17,20,47,60,82,82]$.

Conflicting results have been found for gender differences and sense of direction. Bryant [9] found that males rated their sense of direction higher than females rated their own sense of direction. However, both Kozlowski and Bryant $[42,83]$ found no gender differences in sense of direction. Pedersen [65] administered a self-rating Environmental Competence Scale and found that males rated themselves more competent in wayfinding abilities than females, which indicates that there is a difference in confidence level between males and females. Females reported a higher level of anxiety compared to males about performing spatial tasks, were less confident than males when drawing maps of a floor plan and having a greater feeling of uncertainty when navigating in a building $[45,46,60]$. Most of the studies showed that there were gender differences in wayfinding strategies and accuracy, indicating better performance by males $[44,54,55,86]$.

\subsection{The major aim of the study}

As stated above, in the literature the effects of lighting on visual performance and environmental perception are widely found to be significant. In addition, information processing is one of the three following processes of wayfinding in which environmental perception and spatial cognition interact. The major aim of the current research is to examine the effects of lighting CCT on the wayfinding performance of travellers in airports. Another purpose of this study is examining gender differences in wayfinding performance, since previous studies found that males and females react differently to colour and light $[40,41,90]$.

\section{The experiment}

The null hypotheses of this study are:

1. There is no significant effect of CCT on wayfinding performance.

2. Wayfinding performance of individuals is independent from their gender.

\subsection{Sample group}

The sample group consisted of graduate and undergraduate university students from 21 departments and 26 universities in order to provide a variety. Ninety students were chosen randomly. There were 45 females and 45 males, ranging in age from 19 to $45(\mathrm{~m}=24.84$, std. dev. $=3.66, \mathrm{n}=90$ ). The experiment was conducted with three different sample groups for the three different experiment sets (15 females and 15 males for experiment set $1 ; 15$ females and 15 males for experiment set 2 and 15 females and 15 males for experiment set 3).

\subsection{Selecting the route}

Before the experiment, 15 volunteer tourists and four airport staff were chosen randomly for an unstructured interview in Esenboğa airport. The aim was to understand whether travellers find their way easily or not and how they find it. The density of the circulation area, tourists' profiles, the colour scheme, spatial organization and lighting quality were all examined in order to prepare a generic airport in a VE and select a route for the experiment. Providing an appropriate route representing a real travelling experience was important. According to the knowledge gained from airport staff, people usually asked questions as soon as they entered the airport about how to get to their assigned 


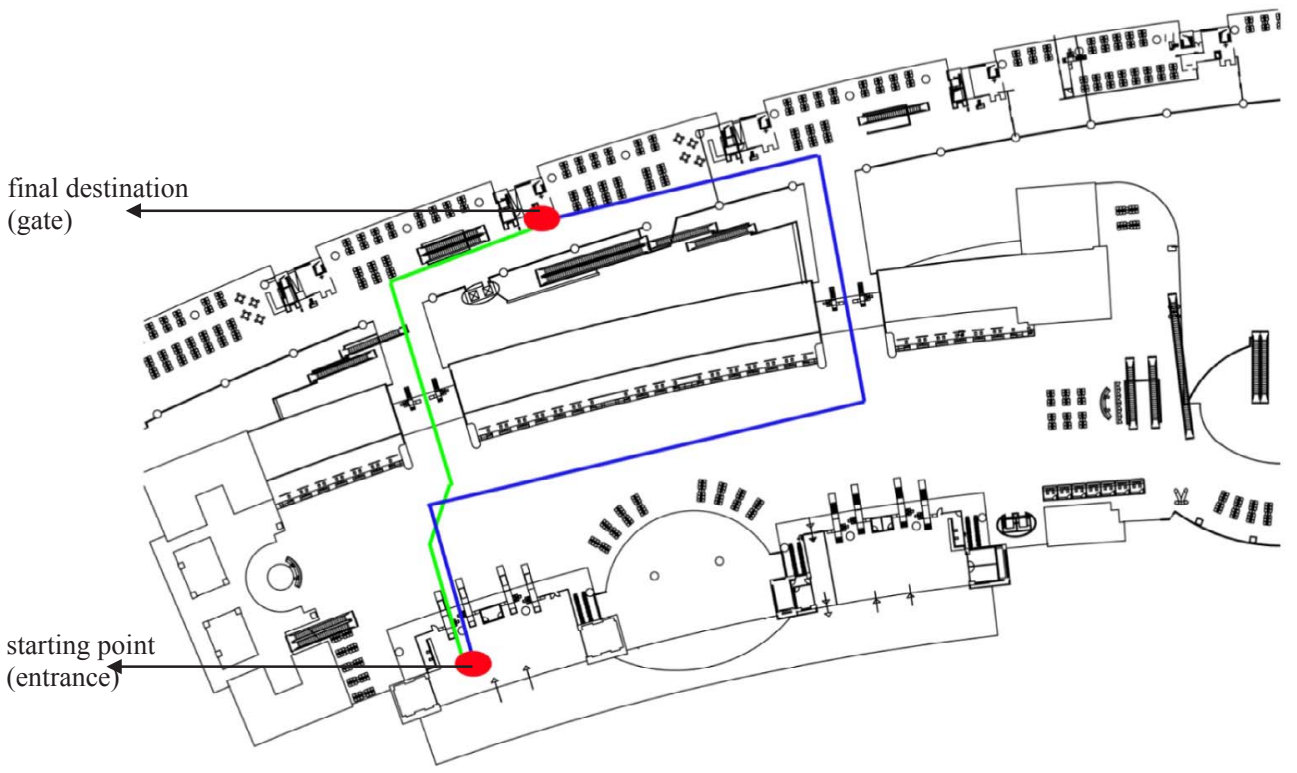

Fig. 1. Partial plan of the airport building showing the selected routes (green line: short route, blue line: long route). (For interpretation of the references to colour in this figure legend, the reader is referred to the web version of this article.) gates. Therefore, the researchers decided to use a route that started at an entrance and ended at a specified gate (see Fig. 1).

\subsection{Modelling}

For this research, VE was preferred because controlling the lighting CCT in an airport is only possible in a VE. 3DS Max was used for modelling and the Mental Ray renderer used to adjust lighting CCTs and illuminance levels, the only renderer that could perform those tasks scientifically. In the actual Esenboğa airport, each camera is located for every six meters, which means 35 images were prepared for each experiment setting and shown to the participants.

\subsection{Experiment settings}

There are three different experiment settings, but the difference between them is in the lighting CCT only. The RGB values of colours are used in interior spaces, and illuminance level and space organization are kept constant for all the experiment settings (Figs. 2-4). The illuminance level recommended for circulation areas in airports is identified as $200 \mathrm{~lx}$, however there are no recommendations identified for CCT of lighting in airports [36]. This study compares three different
CCTs (warm-white, cool-white, and bluish-white) to explore the effects of CCT of lighting on wayfinding performance of travellers in a virtual airport environment (Fig. 5). In the first setting, lighting CCT is set to $3000 \mathrm{~K}$ (yellowish-white). In the second setting, lighting CCT is set to $6500 \mathrm{~K}$ (daylight/neutral white). In the third setting, lighting CCT is set to $12,000 \mathrm{~K}$ (bluish-white).

\subsection{Procedure}

The study was conducted in a single phase. The participants, all volunteers, experienced the desktop VE one by one. A single LED LCD screen of $10.1^{\prime \prime}$ was used in the study. The screen was calibrated as follows: gamma: 1.0 , brightness: 0 , contrast: 50 . The screen resolution was $1024 \times 600$ and the colour quality was 32Bit. The participants were seated at the computer and tested by the researcher. First, the following explanation was read to each participant: "Here is an airport. We will start our tour from the entrance and the gate numbered 109 is the destination. Please direct me after each image with one of the expressions of 'Go right/left/forward/back." During the experiment, the participant listened to the background noise of an airport through earphones to feel a sense of presence. Every six meters, the images were changed by the researcher according to the verbal direction of the

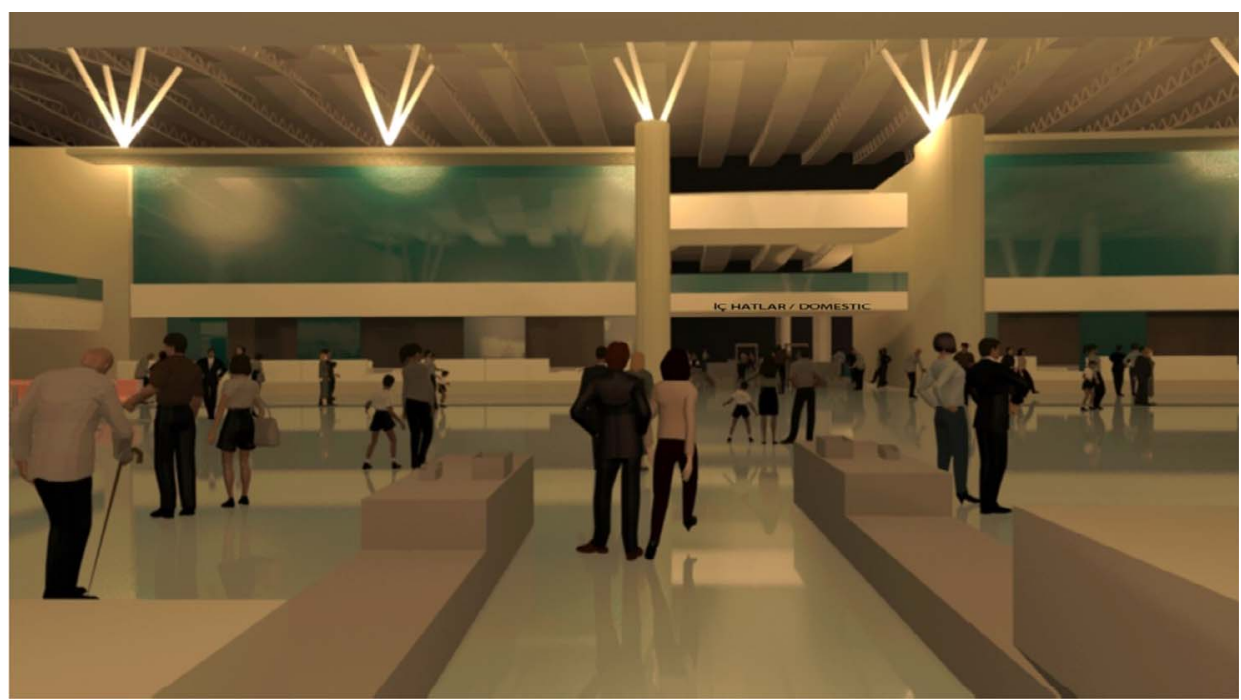

Fig. 2. A VE view illuminated with $3000 \mathrm{~K}$ CCT at $2001 x$. 


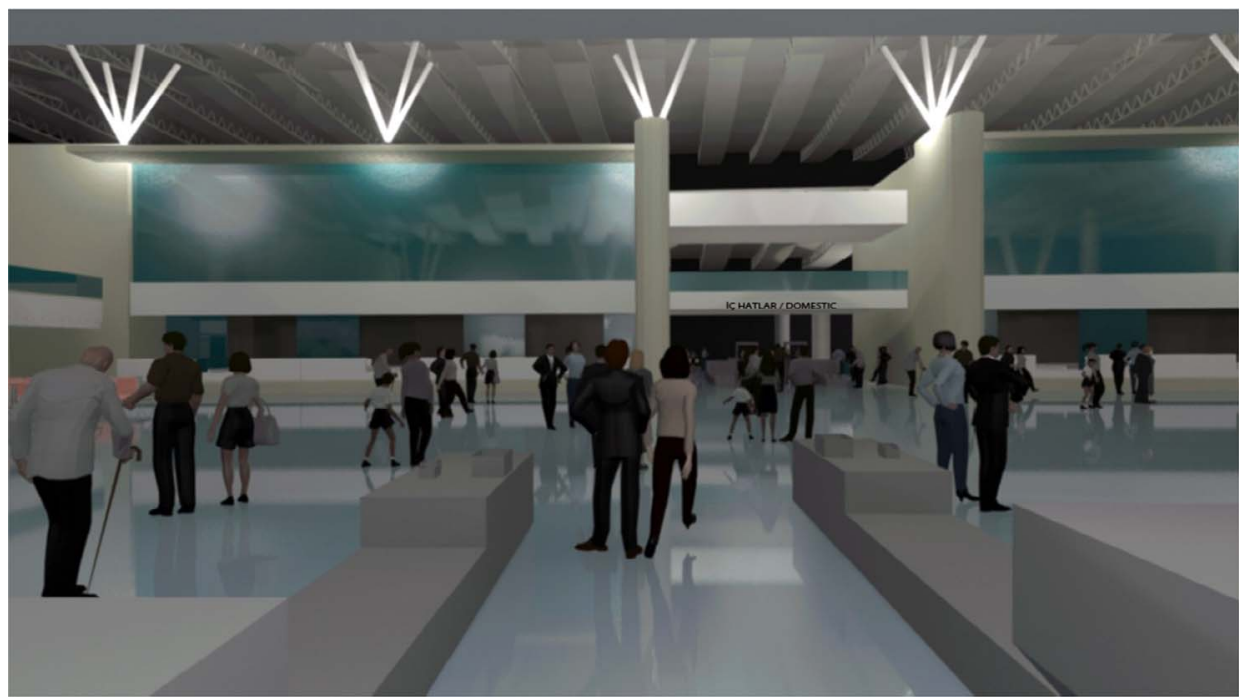

Fig. 3. A VE view illuminated with $6500 \mathrm{~K}$ CCT at $2001 x$.

participant until he or she found the final destination. In the meantime, the directions, time spent, errors, route choices and hesitations of each participant were noted by the researcher.

\section{Findings}

Statistical analyses were conducted regarding the research hypotheses stated in Section 2.

\subsection{Effect of CCT on wayfinding performance}

The effects of CCT on wayfinding performance were evaluated and analysed for the five criteria explained in Section 1.1:

1. Time spent in finding the final destination: The time to reach the final destination was recorded by the researcher for each participant. Time spent is one of the most important factors that measures wayfinding performance.

2. Number of errors in finding the final destination: Each wrong turn was evaluated as an "error" in this study. When the participant went the wrong direction, it was stated to the participant that he or she made a wrong turn, and the participant was directed to the previous image by the researcher and asked to decide again. The same process was repeated at every wrong turn until the final destination was reached.
The case was evaluated as "making an error" and the researcher noted each error point on the experiment sheet.

3. Number of decision points necessary to find the final destination: There were 35 perspective views in each experiment setting at six-meter intervals. The participant directed the researcher after each image by saying "Go right/left/forward/back". Each expression thus indicated a decision at that particular point.

4. Number of hesitation points in finding the final destination: For this study, participants who paused for more than three seconds at a decision point were considered to be experiencing hesitation.

5. Route choice: There were two routes to reach the final destination but one was shorter than the other. Participants' route choices were evaluated as short or long. A sign showing "Domestic" directly in front of the entrance would lead participants to the short route, Some participants, however, ignoring or not noticing the signage, chose to turn right after entering the building and went the long route.

\subsubsection{Time spent in finding the final destination}

The time spent in finding the final destination for the three sample groups (the three experiment sets of Set 1 (3000 K CCT), Set 2 (6500 K CCT) and Set $3(12,000 \mathrm{~K} \mathrm{CCT})$ were assessed by comparing the duration of the wayfinding task. Because the differences between more than two sample groups were compared, and the frequency had skewed

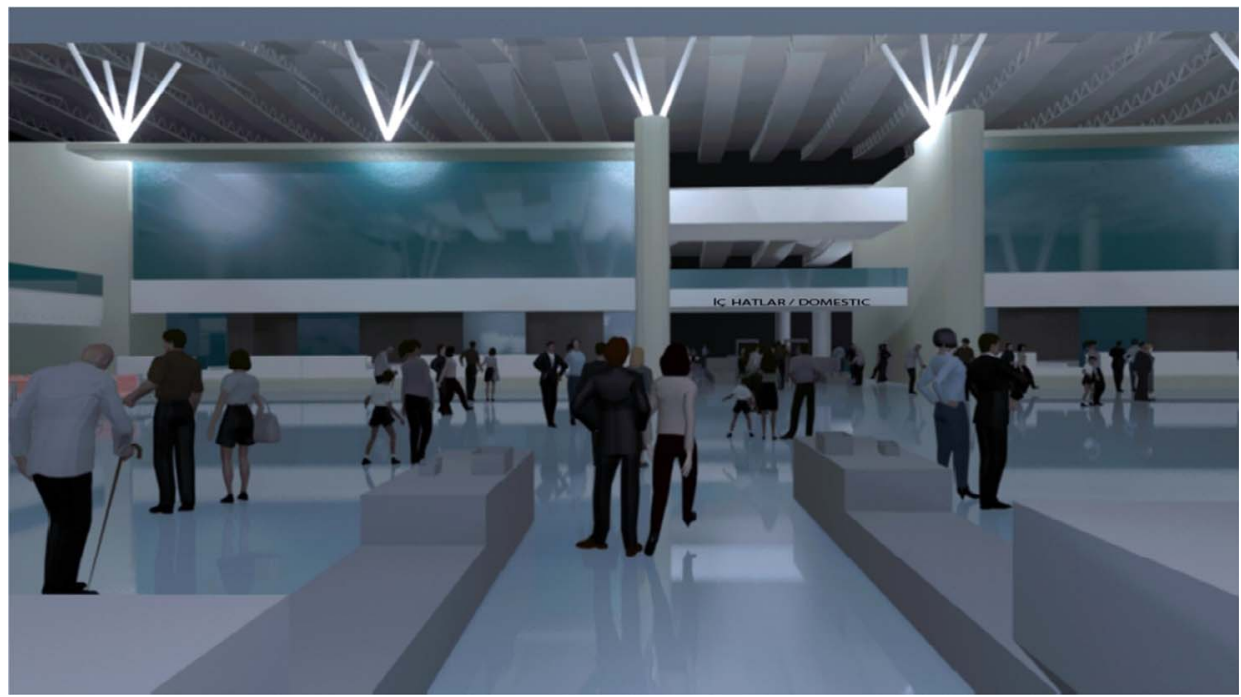

Fig. 4. A VE view illuminated with $12,000 \mathrm{~K} \mathrm{CCT} \mathrm{at}$ $200 \mathrm{~lx}$. 


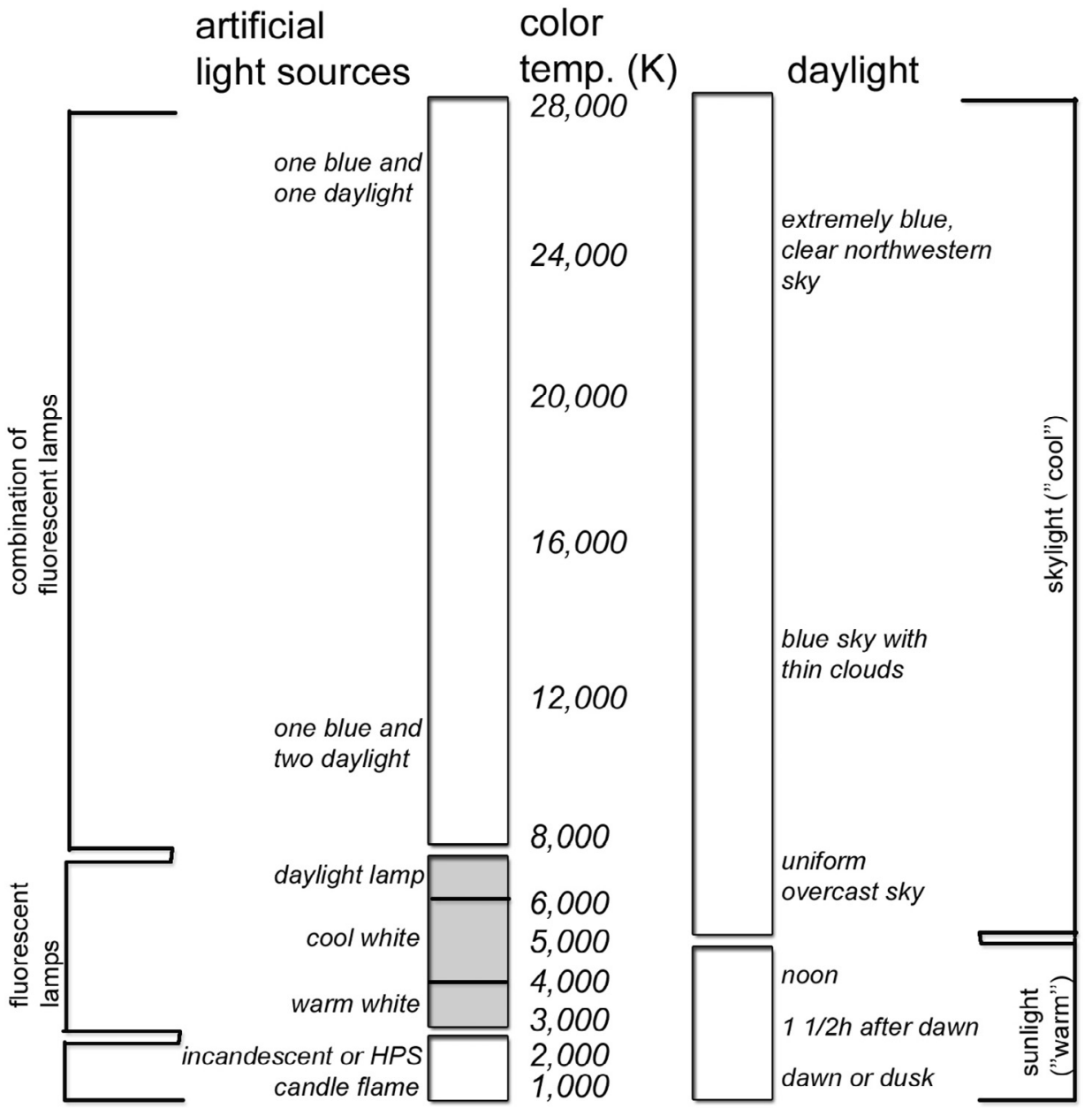

Fig. 5. A chart shows colour temperatures of artificial light sources and daylight (Adapted from: Egan and Olgyay [21]. distribution, the Kruskal Wallis one-way analysis of variance test was used $(\mathrm{m}=125.93$, std. dev. $=53.58, \mathrm{n}=90)$ (Fig. 6). The results indicated that the main effect of CCT on time spent on the wayfinding task was found to be not significant $(\chi 2=2.56$, $\mathrm{df}=2, \mathrm{p}=0.27)$. The proportion of variability in the ranked dependent variable (time spent) accounted for by the CCT variable was 0.02 . Fifty seconds was the minimum time and $329 \mathrm{~s}$ was the maximum time recorded.

\subsubsection{Number of errors in finding the final destination}

First, the total number of errors in finding the final destination was assessed on the Kruskal Wallis one-way analysis of variance test ( $\mathrm{m}=0.67$, std. dev. $0.83, \mathrm{n}=90$ ) (Fig. 6 . The total number of errors means 30 participants' total number of errors for each setting in finding the final destination. The Kruskal Wallis test indicated that the main effect of CCT on the total number of errors was not statistically significant $(\chi 2=0.08, \mathrm{df}=2, \mathrm{p}=0.96)$. The proportion of variability in the ranked dependent variable (number of errors) accounted for by the CCT variable was 0.00 .

\subsubsection{Number of decision points in finding the final destination}

The minimum number of observed decision points was five (walking distance: $30 \mathrm{~m}$ ) and the maximum number of observed decision points was 23 (walking distance: $138 \mathrm{~m}$ ) among the participants $(\mathrm{m}=10.01$, std. dev. $=3.76, \mathrm{n}=90$ ) (Fig. 6 . The Kruskal Wallis test indicated that the effect of CCT on the total number of decision points in finding the final destination was not statistically significant $(\chi 2=0.92, \mathrm{df}=2$, $\mathrm{p}=0.62)$. The proportion of variability in the ranked dependent variable (the number of decision points) accounted for by CCT variable was 0.01 .

\subsubsection{Number of hesitation points in finding the final destination}

First, the total number of hesitation points in finding the final destination of the three sample groups was assessed by comparing the total number of hesitations in the wayfinding task. The total number of hesitation points means 30 participants' total numbers of hesitation points for each setting until reaching the final destination $(\mathrm{m}=1.64$, std. dev. $=1.14, \mathrm{n}=90$ ) (Fig. 6). The Kruskal Wallis test indicated that there was a significant difference between sample groups in terms of the total number of hesitation points in finding the final destination in the whole group $\left(\chi^{2}=13.17, \mathrm{df}=2, \mathrm{p}=0.00\right)$. The proportion of variability in the ranked dependent variable (number of hesitation points) accounted for by the CCT variable was 0.15 , indicating a small relationship between CCT and the number of hesitation points.

Follow-up tests were conducted to evaluate pair-wise differences. The Mann-Whitney $U$ test pointed out that Set 1 (illuminated with 3000 K CCT) showed a significant difference when compared with Set 2 (illuminated with $6500 \mathrm{~K} \mathrm{CCT})(\mathrm{z}=-2.70, \mathrm{p}=0.00)$ and Set 3 (illuminated with $12,000 \mathrm{~K} \mathrm{CCT})(\mathrm{z}=-3.32, \mathrm{p}=0.00)$. However, there was no significant difference between Set 2 (illuminated with $6500 \mathrm{~K}$ CCT) and Set 3 (illuminated with $12,000 \mathrm{~K}$ CCT) $(\mathrm{z}=-1.10$, $\mathrm{p}=0.27$ ). All the statistical analyses verified that lighting significantly contributed to people's wayfinding performance: they hesitated less when finding their way in environments illuminated with $6500 \mathrm{~K}$ or $12,000 \mathrm{~K}$ CCT.

Participants' hesitations were evaluated as 'one or more than one hesitation' and 'no hesitation'. In the experiment sets, 14\% (13 participants) experienced at least one hesitation and $86 \%$ (77 participants) experienced no hesitations when seeking the final destination. As evident in Table 1, Set 3 (illuminated with 12,000 K CCT) had the fewest 


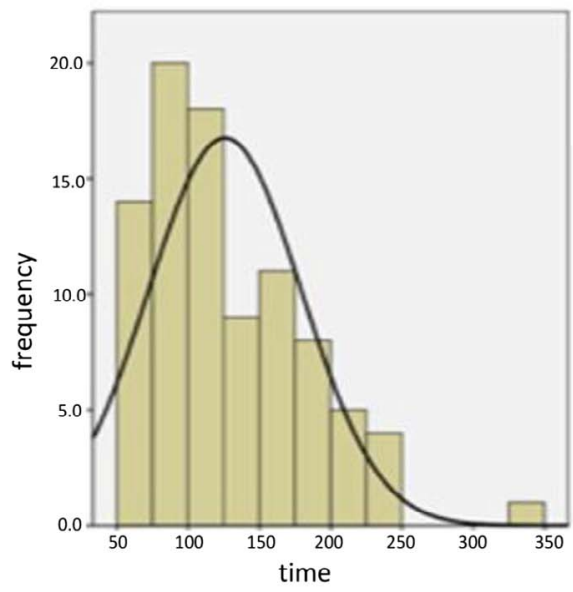

Mean $=125.93$

Std. dev. $=53.585$

$\mathrm{N}=90$
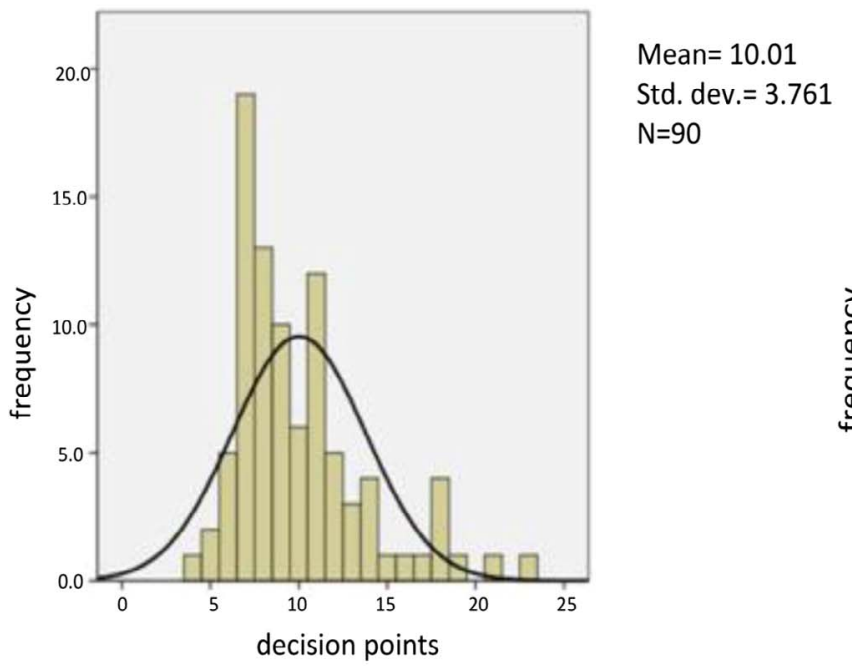

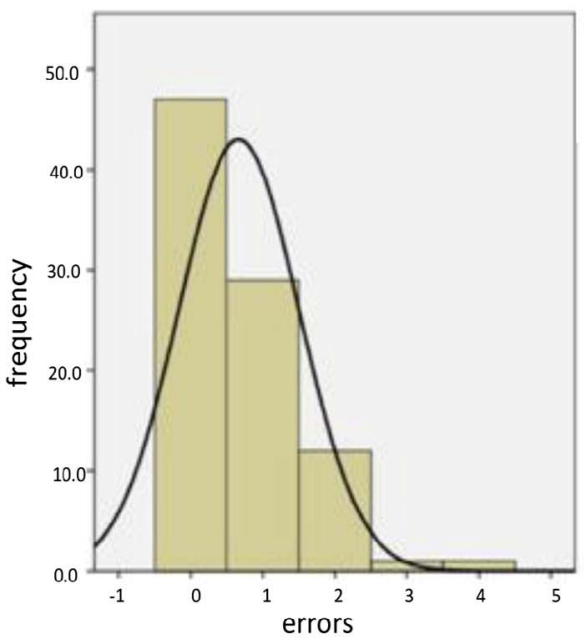

Mean $=.67$

Std. dev. $=.835$

$\mathrm{N}=90$

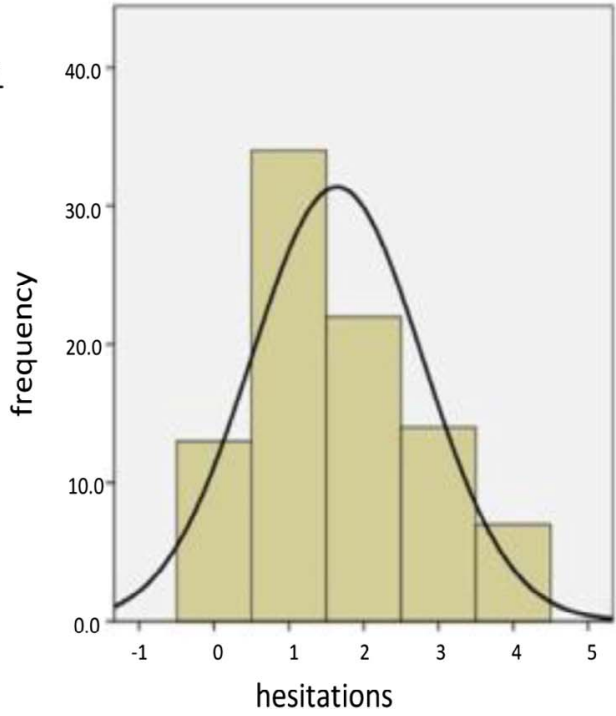

Mean $=1.64$

Std. dev. $=1.145$ $\mathrm{N}=90$

Fig. 6. Frequency distribution graphics.

Table 1

Cross-tabulation for hesitations in finding the final destination with three settings ( $3000 \mathrm{~K}$ $-6500 \mathrm{~K}-12,000 \mathrm{~K}$ ) for the whole group.

\begin{tabular}{lllll}
\hline & $3000 \mathrm{~K}$ & $6500 \mathrm{~K}$ & $1200 \mathrm{~K}$ & Total \\
\hline Hesitate & 29 & 27 & 21 & 77 \\
Not hesitate & 1 & 3 & 9 & 13 \\
Total & 30 & 30 & 30 & 90 \\
\hline
\end{tabular}

number of participants experiencing hesitations and Set 1 (illuminated with $3000 \mathrm{~K}$ CCT) had the most participants who experienced hesitations. The Chi-Square test indicated that there is an association between hesitations and CCT $(\chi 2=9.35, \mathrm{df}=2, \mathrm{p}=0.00)$.

Males Group: The total number of hesitation points in the males groups means 15 participants' total number of hesitation points for each setting while seeking the final destination. The Kruskal Wallis test indicated that there was a significant difference between the males group in terms of the total number of hesitation points when seeking the final destination $\left(\chi^{2}=10.38, \mathrm{df}=2, \mathrm{p}=0.00\right)$. The proportion of variability in the ranked dependent variable (number of hesitation points) accounted for by CCT was 0.24 (i.e., $24 \%$ of variability in the number of hesitation points can be explained by CCT).

The Mann-Whitney test pointed out that Set 1 (illuminated with 3000 K CCT) showed a significant difference when compared with Set 2 (illuminated with $6500 \mathrm{~K} \mathrm{CCT})(\mathrm{z}=-2.42, \mathrm{p}=0.01)$ and Set 3 (illuminated with $12,000 \mathrm{~K}$ CCT $)(\mathrm{z}=-2.82, \mathrm{p}=0.00)$. However, there was no significant difference between Set 2 (illuminated with $6500 \mathrm{~K} \mathrm{CCT}$ ) and Set 3 (illuminated with $12,000 \mathrm{~K} \mathrm{CCT)}(\mathrm{z}=-1.38$, $\mathrm{p}=0.16)$

The findings show that the total number of hesitation points was the least in Set 3 (illuminated with 12,000 K CCT) and increased towards Set 1 (illuminated with $3000 \mathrm{~K} \mathrm{CCT).} \mathrm{All} \mathrm{the} \mathrm{statistical} \mathrm{analyses} \mathrm{verified}$ that lighting significantly contributed to wayfinding performance at $6500 \mathrm{~K} \mathrm{CCT}$ and $12,000 \mathrm{~K} \mathrm{CCT}$ for the males group, as they hesitated less while seeking the destination. This result is in accordance with the whole sample group result, yet the p values are different.

The test observations were also classified as 'one or more than one hesitation' and 'no hesitation.' In the experiment sets, 78\% (35 participants out of 45) experienced at least one hesitation and $22 \%(10$ participants out of 45) experienced no hesitations while finding the final destination. As evident in Table 2, there was a significant

Table 2

Cross-tabulation for hesitations in finding the final destination with the three settings $(3000 \mathrm{~K}-6500 \mathrm{~K}-12,000 \mathrm{~K})$ in the males groups.

\begin{tabular}{lllll}
\hline & $3000 \mathrm{~K}$ & $6500 \mathrm{~K}$ & $12,000 \mathrm{~K}$ & Total \\
\hline Hesitate & 15 & 13 & 7 & 35 \\
Not hesitate & 0 & 2 & 8 & 10 \\
Total & 15 & 15 & 15 & 45 \\
\hline
\end{tabular}


Table 3

Cross-tabulation for hesitations in finding the final destination with the three settings $(3000 \mathrm{~K}-6500 \mathrm{~K}-12,000 \mathrm{~K})$ in the females groups.

\begin{tabular}{lllll}
\hline & $3000 \mathrm{~K}$ & $6500 \mathrm{~K}$ & $12,000 \mathrm{~K}$ & Total \\
\hline Hesitate & 14 & 14 & 14 & 42 \\
Not hesitate & 1 & 1 & 1 & 3 \\
Total & 15 & 15 & 15 & 45 \\
\hline
\end{tabular}

difference in hesitations among the three settings. The Chi-Square test indicated that there was an association between hesitations and CCT $(\chi 2=13.37, \mathrm{df}=2, \mathrm{p}=0.00)$.

Females Group: The Kruskal Wallis test indicated that there was no significant difference among the sample females groups in terms of the number of hesitation points while seeking the final destination $(\chi 2=4.17, \mathrm{df}=2, \mathrm{p}=0.12) .93 \%$ (42 participants out of 45$)$ experienced at least one hesitation and 7\% (3 participants out of 45) experienced no hesitations while seeking the final destination (see Table 3). The Chi-Square test indicated that there was no association between experienced hesitations and CCT for the females groups $(\chi 2=0.00, \mathrm{df}=2, \mathrm{p}=1.00)$. The proportion of variability in the ranked dependent variable (the number of hesitation points) accounted for by CCT was 0.09 .

\subsubsection{Route choice}

The long or short route choice in finding the final destination was assessed by the Kruskal Wallis test. The short route was chosen by $54 \%$ (49 participants) and the long route by $46 \%$ (41 participants). The Kruskal Wallis test indicated that the effect of CCT on route choice in finding the final destination was not significant $(\chi 2=1.15, \mathrm{df}=2$, $\mathrm{p}=0.56$ ). The proportion of variability in the ranked dependent variable (the route choice) accounted for by CCT was 0.01 .

\subsection{Gender difference}

1. Time spent in finding the final destination: Time spent in finding the final destination for three samples in two different groups were assessed by comparing the duration of the wayfinding task. The Wilcoxon signed rank test was used to explore whether there was a gender difference on wayfinding performance throughout the whole participant group. According to the results, there was no significant effect of gender on time spent during wayfinding performance among the three settings $(\mathrm{z}=-0.21, \mathrm{p}=0.82)$.

2. Number of errors in finding the final destination: According to the Wilcoxon test, there was no significant effect of gender on the total number of errors during wayfinding performance among the three settings ( $\mathrm{z}=-0.54, \mathrm{p}=0.58$ ). Of females, $47 \%$ (21 participants) made at least one error and $49 \%$ of males (22 participants) made at least one error. Of females, 53\% (24 participants) made no errors while seeking the final destination, whereas $51 \%$ of males (23 participants) made no errors.

3. Number of decision points in finding the final destination: According to the Wilcoxon test, there was no significant effect of gender on the total number of decision points during wayfinding performance among the three settings $(\mathrm{z}=-0.78, \mathrm{p}=0.43)$.

4. Number of hesitation points in finding the final destination: Of females, 93\% (42 participants) experienced at least one hesitation, whereas $78 \%$ of males (35 participants) experienced at least one hesitation. Of females, 7\% (3 participants) experienced no hesitations while seeking the final destination, whereas $22 \%$ of males (10 participants) experienced no hesitations. According to the Wilcoxon test, there was a significant effect of gender on experiencing hesitation or not during wayfinding performance among the three settings $(\mathrm{z}=-1.94, \mathrm{p}=0.05)$.

5. Route choice: According to the Wilcoxon test, there was no significant effect of gender on route choice during wayfinding performance among the three settings $(\mathrm{z}=-0.19, \mathrm{p}=0.84)$. Participants were evaluated as selecting the short or long route.

\subsection{Other findings}

1. Correlations between time spent in finding the final destination and the number of hesitations in the whole group: According to the result of the Spearman Correlation test, there was a significant medium-level positive correlation between time spent finding the final destination and number of hesitations (corr $=0.65$, at 0.01 level - two tailed). Thus, the participants took more time when they experienced more hesitations while they were finding their way.

2. Correlations between time spent in finding the final destination and number of errors: According to the result of the Spearman Correlation test, a significant medium-level correlation was found. Time spent finding the final destination and number of errors were in positive correlation (corr $=0.64$, at 0.01 level - two tailed). The more the participants made errors, the more time they needed to find the final destination.

3. Correlations between number of decision points and errors: According to the result of the Spearman Correlation test, there was a significant medium-level positive correlation between the number of decision points and errors (corr $=0.64$, at 0.01 level- two tailed). Thus, participants made more errors when they stopped more often (as decision points) while they were finding their way.

4. Correlations between number of hesitation points and decision points: According to the result of the Spearman Correlation test, a significant medium-level correlation was found. Number of hesitations and decision points were in positive correlation (corr $=0.64$, at 0.01 level- two tailed). The more the participants hesitated, the more decision stops (at decision points) they needed.

\section{Discussion}

In this study, the researcher examined the effect of CCT on wayfinding in airports in a virtual environment. It was hypothesized that there are differences between different CCTs in wayfinding performance. Participants' performances were compared under three different colour temperatures $(3000 \mathrm{~K}, 6500 \mathrm{~K}$ and $12,000 \mathrm{~K})$, considering the following topics: (a) time spent in finding the final destination, (b) number of errors in finding the final destination, (c) number of decision points in finding the final destination, (d) number of hesitation points in finding the final destination and (e) route choice.

The results showed some similarities to and differences from wayfinding performance findings in the literature. The current study found that there was no effect of any CCT in terms of time spent, number of errors, number of decision points or route choice, and that there was no significant effect of gender on wayfinding performance in the whole participant group. Chebat et al. [11] conducted a study, using actual shoppers in a shopping mall, which showed the relationship between gender and time necessary to find a specified store. Time spent during the wayfinding performance was also one of the measurements of evaluation in the current study. The results of Chebat et al. [11] showed that men spent more time than women, which conflicts with this study as no gender difference was found in time spent. Nevertheless, it should be noted that the difference might be due to the different environments (shopping mall vs. airport) used.

Tlauka et al. [82] explored gender differences in spatial knowledge that was acquired through a simulated exploration of a virtual shopping centre. Time spent and numbers of errors were measurements for the evaluation of that wayfinding task. It was found that female participants required more time to travel from the start location to the finish location when following a route through the simulated shopping centre, and while following the route, females made more errors. This finding also conflicts with the present study, as no gender difference was found 
in time spent and number of errors, but again, this might be due to the settings (shopping mall vs. airport).

Choi et al. [12] investigated gender -specific relationships between route-learning strategies and abilities in a university building. Number of decision points (route distance), route choice, frequencies of hesitations and number of errors (wrong turns) were the measurements for that evaluation of a route task. The results indicated that males used a significantly shorter route than females did, which conflicts with the results of the present study except at $12,000 \mathrm{~K}$ CCT. Again, this difference might be due to the difference in settings (university building vs. airport). Choi et al. [12] found that males used a shorter route compared to females. This study confirms that finding, except at 12,000 K CCT, where males used a shorter route than females.

According to the studies stated above, there are several different results in wayfinding performance in terms of: time spent, number of errors, number of decision points, number of hesitations and route choices. However, the variables of all these studies were different from this study. To the researcher's knowledge, there are no studies measuring the effects of lighting CCT on travellers' wayfinding performance. Nevertheless, the results of this study could be evaluated according to previous studies in terms of gender. While Chebat et al. [11] found men spent more time than women in their wayfinding task, Tlauka et al. [82] found females requiring more time. Chebat et al.'s [11] study was conducted in a real-world environment and Tlauka et al. [82] used a VE, but both used shopping centres. In the current study no significant difference was found between men and women in time spent on the wayfinding task.

There are some studies on the effects of lighting CCT, yet they concentrated on performance tasks other than wayfinding. Manav and Küçükdoğu [51] evaluated the performance of 56 office workers through asking questions; the speed of answering questions and making errors were considered factors affecting workers' performance. They investigated the effects of CCT and illuminance level on performance by comparing four different illuminance levels (500, 750, 1000 and $2000 \mathrm{~lx}$ ) and three different CCTs $(4000 \mathrm{~K}, 2700 \mathrm{~K}$ and a mixed CCT). The experiment determined that illuminance level is not a factor affecting performance on its own, yet CCT does have a significant effect on performance in terms of making errors and the speed of answering questions. It is observed that in a setting under mixed CCT at $500 \mathrm{~lx}$, the mean average of making errors was maximum. No gender differences were found in Manav and Küçükdoğu's [51] study. The current study, also testing a cognitive task, mirrors Manav and Küçükdoğu's [51] results in terms of gender, as it found no gender differences except for in experiencing hesitation.

Knez [39] evaluated 96 participants doing several cognitive tasks (long-term recall and recognition, problem-solving, free recall, performance appraisal and a mood and room light evaluation task). Knez investigated the effect of indoor lighting on cognitive performance via mood by comparing two illuminance levels (dim $300 \mathrm{~lx}$ vs. bright $1500 \mathrm{~lx}$ ), two CCTs (a $3000 \mathrm{~K}$ "warm" white vs. a $4000 \mathrm{~K}$ "cool” white) at high CRI (95). The experiment showed that CCT may induce a positive mood and enhance long-term recognition and problem solving in males and females. According to the above noted studies, CCT has an effect on two-dimensional paper-based cognitive tasks, yet there has been no study measuring the effect of CCT on wayfinding performance. Arthur and Passini [4] described wayfinding as a problem-solving cognitive performance comprising the following processes: decision making, decision executing and information processing. Different from Manav and Küçükdoğu [51] and Knez [39], the current study found no significant effect of CCT on making errors, which might be explained by the location differences between the actual tests.

The current study found that CCT has a significant effect on the number of hesitation points in the whole participants group ( $\mathrm{p}=0.00$ ). The $3000 \mathrm{~K}$ CCT set (1) showed a significant difference when compared with the $6500 \mathrm{~K}$ CCT set (2) and the $12,000 \mathrm{~K}$ CCT set (3) $(\mathrm{p}=0.00$, $\mathrm{p}=0.00$ ). However, there was no significant difference between
$6500 \mathrm{~K} \mathrm{CCT} \mathrm{(set} \mathrm{2)} \mathrm{and} \mathrm{12,000} \mathrm{K} \mathrm{CCT} \mathrm{(set} \mathrm{3)} \mathrm{(p} \mathrm{=} \mathrm{0.27).} \mathrm{It} \mathrm{also} \mathrm{found}$ that CCT has a significant effect on user hesitation while finding their route. Participants who did the experiment under $6500 \mathrm{~K}$ CCT (set 2) and $12,000 \mathrm{~K} \mathrm{CCT} \mathrm{(set} 3$ ) were significantly more confident in finding their final destination, hesitating less often. The males group was affected by CCT in terms of hesitations $(p=0.00)$, and the Wilcoxon signed rank test indicated that there was a significant effect of gender on experiencing hesitation or not during the wayfinding performance between the three settings ( $\mathrm{p}=0.05$ ).

Coluccia and Louse [15], Devlin and Bernstein [20], Lawton et al. [45], Moffat et al. [56], Sandstrom et al. [76] and Saucier et al. [77] all indicated that wayfinding time is significantly correlated with errors (wrong turns) and hesitation frequencies. Travellers who experienced more errors and hesitations spent more time seeking the destination. This study confirms those findings, as it determined a positive correlation between time spent and number of errors, and also between time spent and number of hesitations.

Travelling is one of the most stressful wayfinding processes, as travellers may already feel stressed, and feeling disoriented may cause psychological and physiological reactions. This study found that CCT has a significant effect on wayfinders' hesitations, thus these results can be used to enhance travellers wayfinding experiences.

\section{Conclusion and suggestions for future research}

The literature shows that wayfinding studies mostly concentrate on colour, landmarks, familiarity, signage systems, spatial differences, plan layout and user behaviour, but not that much on lighting effects. The CCT studies in the literature, on the other hand, seem to concentrate on perception, individual liking, working performance and psychological and physiological effects. There is no research concentrating on the relationship between CCT and wayfinding performance. Airports are one of the most important public spaces in this global world, and as a growing number of people choose to travel by plane, it is important to analyse the type of environment provided for travellers. In airport environments, passenger circulation and wayfinding are prominent issues. While wayfinding is more easily accomplished in regional airports, it becomes more challenging as the level of traveller and flight traffic increases at national and international airports, particularly those with high percentages of connecting travellers and significant volumes of domestic and international travellers [27]. For this study, a generic small scale airport's domestic flights department is analysed, however future researchers can extend the discussion building upon the results of found in.

Moreover, the participant group is limited to university students for this study, but it should not be neglected that this study gives the preliminary results of the relationship between CCT and wayfinding performance in a virtual airport environment. Future research should generate a bigger sample group to represent the variety of users of an airport.

The findings of this experiment may provide some clues not only for interior architects but also for environmental psychologists who may be interested in different factors affecting user behaviour. Additionally, airport managers can benefit from the results of this study which explains the effect of CCT of lighting on wayfinding performance of travellers in an airport circulation area. The suggestion originated from this research is the fact that yellowish-white lighting (3000 K) CCT causes anxiety in wayfinding behaviour, increased hesitations and number of errors of travellers and therefore should not be used in the circulation areas of airport lighting.

\section{Appendix A. Supplementary material}

Supplementary data associated with this article can be found, in the online version, at http://dx.doi.org/10.1016/j.displa.2018.01.003. 


\section{References}

[1] E. Aksagür, Effects of surface colors on walls under different light sources on the perceptual magnitude of space in a room, in: Color 77: Proceedings of the 3rd Congress of the International Color Association, New York, 1977, pp. 388-391.

[2] W.S. Albert, R.A. Rensink, J. Beusmanns, Learning relative directions between landmarks in a desktop virtual environment, Spatial Cognit. Comput. 1 (1999) 131-144.

[3] M.J. Allen, R. Hogeland, Spatial problem-solving strategies as functions of sex, Percept. Mot. Skills 47 (1978) 348-350.

[4] P. Arthur, R. Passini, Wayfinding: People, Signs, and Architecture, McGraw-Hill, Toronto, 1992.

[5] G.A. Best, Direction finding in large buildings, Architectural Psychol. (1970) 72-91.

[6] B.M. Biner, D.L. Butler, An arousal optimization model of lighting level preferences, Environ. Behav. 21 (1989) 3-16.

[7] M.H. Bornstein, On light and the aesthetics of color: Lumia kinetic art, Leonardo 8 (1975) 203-212.

[8] P.R. Boyce, Cuttle, Effect of correlated color temperature on the perception of in teriors and colour discrimination performance, Light Res. Technol. 22 (1) (1990) $19-36$.

[9] K.J. Bryant, Personality correlates of sense of direction and geographical orientation, J. Pers. Soc. Psychol. 43 (1982) 1318-1324.

[10] L. Castelli, L. Corazzini, G. Geminiani, Spatial navigation in large-scale virtual environments: gender differences in survey tasks, Comput. Hum. Behav. 24 (2008) $1643-1667$.

[11] J.C. Chebat, C.G. Chebat, K. Therrien, Gender-related wayfinding time of mall shoppers, J. Business Res. 61 (2008) 1076-1082.

[12] J. Choi, E. McKillop, M. Ward, N. L'Hirondelle, Sex-specific relationships between route-learning strategies and abilities in a large-scale environment, Environ. Behav. 38 (2006) 791.

[13] J.M. Cimadevilla, R. Cánovas, L. Iribarne, A. Soria, L. López, A virtual-based task to assess place avoidance in humans, J. Neurosci. Methods 196 (2011) 45-50.

[14] E. Coluccia, G. Iosue, M.A. Brandimonte, The relationship between map drawing and spatial orientation abilities: A study of gender differences, J. Environ. Psychol. 27 (2) (2007).

[15] E. Coluccia, G. Louse, Gender differences in spatial orientation: A review, J. Environ. Psychol. 24 (2004) 329-340.

[16] E. Cubukcu, J.L. Nasar, Relation of physical form to spatial knowledge in largescale virtual environments, Environ. Behav. 37 (3) (2005) 397-417.

[17] E. Cubukcu, J.L. Nasar, Influence of physical characteristics of routes on distance cognition in virtual environments, Environ. Planning B: Planning Design 32 (5) (2005) 777-785.

[18] R.P. Darken, J.L. Silbert, Navigating large virtual spaces, Int. J. Hum.-Comput. Interact. 8 (1996) 49-71.

[19] R.G. Davis, D.N. Ginthner, Correlated color temperature, illuminance level, and the Kruithof curve, J. Illuminating Eng. Soc. 19 (1990) 27-38.

[20] A.D. Devlin, J. Bernstein, Interactive wayfinding: Use of cues by men and women, J. Environ. Psychol. 15 (1995) 23-38.

[21] M.D. Egan, V. Olgyay, Architectural Lighting, second ed., McGraw-Hill, Boston, 2002.

[22] K.R. Fehrman, C. Fehrman, Colour: The Secret Influence, Prentice-Hall, New Jersey, 2000.

[23] S. Fleischer, H. Krueger, C. Schierz, Effect of brightness distribution and light colors on office staff: results of the 'lighting harmony' project, in: The 9th European Lighting Conference "Lux Europa 2001", Reykjavik, 2001, pp. 77-80.

[24] J.E. Flynn, A.W. Segil, G.R. Steffy, Architectural Interior Systems: Lighting, Acoustics, Air Conditioning, second ed., Van Nostrand Reinhold, New York, 1988.

[25] S.A. Fotios, G.J. Levermore, The effect of lamp color properties upon CIE Symposium paper, 1999.

[26] L.A. Galea, D. Kimura, Sex differences in route-learning, Pers. Indiv. Diff. 14 (1) (1993) 53-65.

[27] C.J. Gentry, Drawn Cognitive Maps of Environmental Perceptions and Expectations in the Des Moines International Airport, Iowa State University, 2010.

[28] S. Gillner, H. Mallot, Navigation and acquisition of spatial knowledge in a virtua maze, J. Cognit. Neurosci. 10 (1998) 445-463.

[29] R.G. Golledge, Wayfinding Behavior: Cognitive Mapping and Other Spatial Processes, Johns Hopkins University Press, Baltimore, 1999.

[30] E. Heineken, P. Schulte, Acquiring distance knowledge in virtual environments Paper presented at the RIO HFM Workshop on "What is essential for virtual reality systems to meet human performance goals?," held in The Hague, The Netherlands, and published in RTO MP-058, 2000.

[31] E. Helvacioğlu, N. Olguntürk, Color contribution to children's wayfinding in school environments, Opt. Laser Technol. 43 (2011) 410-419.

[32] M.L. Hidayetoglu, K. Yıldırım, A. Akalın, The effects of colour and light on indoor wayfinding and the evaluation of the perceived environment, J. Environ. Psychol. 32 (1) (2012) 50-58.

[33] J.V. Hoof, A.M.C. Schoutens, M.P.J. Aarts, High color temperature lighting for in stitutionalised older people with dementia, Build. Environ. 44 (2009) 1959-1969.

[34] R.W.G. Hunt, Measuring Colour, John Wiley \& Sons, New York, 1987.

[35] T. Iachini, I. Sergi, G. Ruggiero, A. Gnisci, Gender differences in object location memory in a real three-dimensional environment, Brain Cogn. 59 (2005) 52-59.

[36] Illuminating Engineering Society of North America, The IESNA Lighting Handbook: Reference \& Application, Illuminating Engineering Society of North America, 2000.

[37] P. Jansen-Osmann, B. Berendt, Investigating distance knowledge using virtual environments, Environ. Behav. 34 (2002) 178-193.
[38] S. Kanaya, K. Hashinato, E. Kichize, Subjective balance between general colour rendering index, color temperature and illuminance of interior lighting, in: Proceedings of CIE 19th Session, 274278, Kyoto, 1979.

[39] I. Knez, Effects of indoor lighting on mood and cognition, J. Environ. Psychol. 15 (1995) 39-51.

[40] I. Knez, Effects of colour of light on nonvisual psychological processes, J. Environ. Psychol. 21 (2001) 201-208.

[41] I. Knez, C. Kers, Effects of indoor lighting, gender, and age on mood and cognitive performance, Environ. Behav. 6 (2000) 817-831.

[42] L.T. Kozlowski, K.J. Bryant, Sense of direction, spatial orientation, and cognitive maps, J. Exp. Psychol. 3 (1977) 590-598.

[43] C.A. Lawton, Gender differences in way-finding strategies: Relationship to spatial ability and spatial anxiety, Sex Roles 30 (1994) 765-779.

[44] C.A. Lawton, Strategies for indoor wayfinding: The role of orientation, J. Environ. Psychol. 16 (1996) 137-145.

[45] C.A. Lawton, S.I. Charleston, A.S. Zieles, Individual and gender related differences in indoor wayfinding, Environ. Behav. 28 (1996) 204-219.

[46] C.A. Lawton, J. Kallai, Gender differences in wayfinding strategies and anxiety about wayfinding: a cross-cultural comparison, Sex Roles 47 (9-10) (2002) 389-401.

[47] C.A. Lawton, K.A. Morrin, Gender differences in pointing accuracy in computersimulated 3D mazes, Sex Roles 40 (1) (1999) 73-92.

[48] I. León, L. Tascón, J.M. Cimadevilla, Age and gender-related differences in a spatial memory task in humans, Behav. Brain Res. 306 (2016) 8-12.

[49] M.C. Linn, A.C. Petersen, Emergence and characterization of sex differences in spatial ability: A meta-analysis, Child Dev. 56 (1985) 1479-1498.

[50] B. Manav, An experimental study on the apprasial of the visual environment at offices in relation to color temperature and illuminance, Build. Environ. 42 (2007) 979-983.

[51] B. Manav, M.Ş. Küçükdoğu, The impact of illuminance and color temperature on performances at offices, J. Istanbul Technical Univ. 5 (2006) 1-25.

[52] B. Manav, C. Yener, Effects of different lighting arrangements on space perception, Architectural Sci. Rev. 42 (1999) 43-47.

[53] M.G. McGee, Human spatial abilities: psycho-metric studies and environmental, genetic, hormonal, and neurological infuences, Psychol. Bull. 86 (1979) 889-918.

[54] D. McGuiness, J. Sparks, Cognitive style and cognitive maps: sex differences in representations of a familiar terrain, J. Mental Imagery (1983).

[55] L.K. Miller, V. Santoni, Sex differences in spatial abilities: strategic and experiential correlates, Acta Psychol. 62 (3) (1986) 225-235.

[56] S.D. Moffat, E. Hampson, M. Hatzipantelis, Navigation in a virtual maze: Sex differences and correlation with psychometric measure of spatial ability in humans, Evol. Hum. Behav. 19 (1998) 73-87.

[57] A.H. Munsell, A Colour Notation, Macbeth, Baltimore, Maryland, 1988.

[58] R. Nori, L. Piccardi, I believe I'm good at orienting myself...But is that true? Cog. Process 16 (2015) 301-307.

[59] S. Odabaşığlu, N. Olguntürk, Effects of colored lighting on the perception of in terior spaces, Percept. Mot. Skills 120 (1) (2015) 1-19.

[60] E.M. O'Laughlin, B.S. Brubaker, Use of landmarks in cognitive mapping: gender differences in self report versus performance, Pers. Indiv. Diff. 24 (5) (1998) 595-601.

[61] P.J. Osmann, Using desktop virtual environments to investigate the role of landmarks, Comput. Hum. Behav. 18 (2002) 427-436.

[62] P.J. Osmann, G. Wiedenbauer, The representation of landmarks and routes in children and adults: A case study in a virtual environment, J. Environ. Psychol. 24 (2004) 347-357.

[63] M. Palmiero, R. Nori, C. Rogolino, S. D'Amico, L. Piccardi, Sex differences in visuospatial and navigational working memory: the role of mood induced by background music, Exp. Brain Res. 234 (2016) 2381-2389.

[64] R. Passini, Wayfinding in Architecture, Van Nostrand Reinhold, New York, 1984.

[65] D.M. Pedersen, Dimensions of environmental competence, J. Environ. Psychol. 19 (3) (1999) 303-308.

[66] J. Peponis, C. Zimring, Y.K. Cho, Finding the building in wayfinding, Environ. Behav. 22 (1990) 555-590.

[67] L. Piccardi, F. Bianchini, L. Iasevoli, G. Giannone, C. Guariglia, Sex differences in a landmark environmental re-orientation task only during the learning phase, Neurosci. Lett. 503 (2011) 181-185.

[68] R. Raskin, Colour: An Outline of Terms and Concepts, Aarhus University Press, Denmark, 1986.

[69] M. Raubal, M. Egenhofer, Comparing the complexity of wayfinding tasks in built environments, Environ. Planning B 25 (6) (1998) 895-913.

[70] A.E. Richardson, D.R. Montello, M. Hegarty, Spatial knowledge acquisition from maps and from navigation in real and virtual environments, Memory Cognit. 27 (1999) 741-750.

[71] R.A. Ruddle, S. Lessels, Three levels of metric for evaluating wayfinding presence, Presence 15 (6) (2006) 637-654.

[72] R.A. Ruddle, S.J. Payne, D.M. Jones, Navigation buildings in desktop virtual environments: Experimental investigations using extended navigational experience, J. Exp. Psychol. 3 (1997) 143-159.

[73] R.A. Ruddle, S.J. Payne, D.M. Jones, Navigating large-scale "desktop" virtual buildings: Effects of orientation aids and familiarity, Presence 7 (1998) 179-192.

[74] R.A. Ruddle, P. Peruch, Effects of proprioceptive feedback and environmental characteristics on spatial learning in virtual environments, Int. J. Hum Comput Stud. 60 (2004) 299-326.

[75] R.A. Ruddle, S.J. Payne, D.M. Jones, The effect of maps on navigation and search strategies in very- large-scale virtual environments, J. Environ. Psychol. 5 (1999) $54-75$ 
[76] N.J. Sandstrom, J. Kaufman, S.A. Huettel, Males and females use different distal cues in a virtual environment navigation task, Cognitive Brain Res. 6 (1998) 351-360.

[77] D.M. Saucier, S.M. Green, J. Leason, A. MacFadden, S. Bell, L.J. Elias, Are sex differences in navigation caused by genderually dimorphic strategies or by differences in the ability to use the strategies? Behav. Neurosci. 116 (3) (2002) 403-410.

[78] K. Stanney, G. Salvendy, After effects and sense of presence in virtual environments: formulation of a research and development agenda, Int. J. Hum.-Comput. Interact. 10 (1998) 135-187.

[79] L. Tascón, I. León, J.M. Cimadevilla, Viewpoint-related gender differences in a spatial recognition task, Learn. Indiv. Diff. 50 (2016) 270-274.

[80] L.H. Taylor, E.W. Socov, The movement of people toward light, Journal of IES, 74, 237-241; in Illuminating Engineering Society of North America. 2000. The IESNA lighting handbook: Reference \& Application Illuminating Engineering Society of North America, 1974.

[81] D.K. Tiller, J.A. Veitch, Perceived room brightness: Pilot study on the effect of luminance distribution, Light. Res. Technol. 27 (1995) 93-101.

[82] M. Tlauka, A. Brolese, D. Pomeroy, W. Hobbs, Gender differences in spatial knowledge acquired through simulated exploration of a virtual shopping centre, J. Environ. Psychol. 25 (2005) 111-118.
[83] S.G. Vanderberg, A.R. Kuse, G.P. Vogler, Searching for correlates of spatial ability, Percept. Mot. Skills 60 (1985) 343-350.

[84] D. Veldkamp, F. Hagethorn, B. Kröse, P. De Greef, The use of visual landmarks in a wayfinding system for elderly with beginning dementia. In the Proceedings of Mede-Tel 2008, CD-ROM, 161-165, Luxembourg, 2008.

[85] D. Waller, D. Knapp, E. Hunt, Spatial representation of virtual mazes: The role of visual fidelity and individual differences, Hum. Factors 43 (2001) 147-158.

[86] S.L. Ward, N. Newcombe, W.F. Overton, Turn left at the church, or three miles north: a study of direction giving and sex differences, Environ. Behav. 18 (2) (1986) 192-213.

[87] S.J. Westerman, T. Cribbin, R. Wilson, Virtual information space navigation: Evaluating the use of head tracking, Behav. Inf. Technol. 20 (2001) 419-426.

[88] P. Willemsen, A.A. Gooch, Perceived egocentric distances in real image-based and traditional virtual environments, in: M. Macedonia, T. Susumu (Eds.), The Proceedings of the IEEE virtual reality 2002, Computer Society, Orlando, 2002, pp. 275-276.

[89] B.G. Witmer, J.H. Bailey, B.W. Knerr, K.C. Parsons, Virtual spaces and real world places: Transfer of route knowledge, Int. J. Hum Comput Stud. 45 (1996) 413-428.

[90] K. Yıldırım, A. Akalın-Başaya, M.L. Hidayetoğlu, Effects of indoor color on mood and cognitive performance, Build. Environ. 42 (2007) 3233-3240. 